\title{
O CONTEÚDO DE REPRODUÇÃO HUMANA NO ENSINO FUNDAMENTAL: PERCEPCCÃO DOS PROFESSORES E ALUNOS E O USO DE DIFERENTES RECURSOS DIDÁTICOS
}

\author{
THE CONTENT OF HUMAN REPRODUCTION IN ELEMENTARY EDUCATION: \\ PERCEPTION OF TEACHERS AND STUDENTS AND THE USE OF DIFFERENT \\ TEACHING RESOURCES
}

Larissa Fracalossi Lucas ${ }^{1}$, Juliana Castro Monteiro Pirovani ${ }^{2}$, Marcos da Cunha Teixeira ${ }^{3}$, Camila Galletti Corrêa ${ }^{4}$

Recebido: março/2020 Aprovado: outubro/2021

\begin{abstract}
Resumo: O presente estudo teve como objetivo analisar como o conteúdo de reprodução humana é ministrado, quais dificuldades encontradas pelos professores e alunos e, além disso, avaliar o uso diferentes recursos didáticos. Uma pesquisa foi feita com 18 professores da de escolas públicas e particulares e seis diferentes recursos didáticos no ensino de reprodução humana foram utilizados com duas turmas do 8ㅇ ano do ensino fundamental da Escola Estadual de Ensino Fundamental e Médio (EEEFM) "Pio XII", no município de São Mateus-ES. Para coleta de dados foram aplicados questionários semiestruturados para os professores e alunos. Os professores demonstraram interesse em trabalhar o tema, mas possuem dificuldades para controlar a euforia da turma, estimular o interesse dos alunos e com os recursos oferecidos pela escola. A maioria tem utilizado recursos didáticos em suas aulas, porém a falta de apoio da escola e falta de tempo para planejar faz com que o uso dos recursos ainda fique muito limitado. Diante das falas dos alunos, os diferentes recursos estimularam a vontade de aprender, a compreender melhor o conteúdo, a tirar dúvidas e ter uma visão mais clara da matéria. Desse modo, ficou evidente que os recursos didáticos ajudaram no processo de ensino/aprendizagem.
\end{abstract}

Palavras-chave: ensino básico, ciências, aprendizagem significativa.

Abstract: This research has had as an objective the analysis of how the content about human reproduction is taught, which difficulties are faced by the teachers and students and in addition the evaluation about the use of different teaching resources. Therefore, a survey was realized with 18 teachers from public and private schools. Besides, six different teaching resources in the teaching of human reproduction were used with two 8th year of elementary school classes, in State Elementary and High School (EEEFM) "Pio XII", in the city of São Mateus-ES. Semi-structures questionnaires were applied to teachers and students in order to collect the data. The teachers showed interest in working the topic. However, they faced difficulties in controlling the class' euphoria, stimullating students' interest and also how to deal with the resources offered by the school. Most of the teachers have been using teahcing resources in their classes, although the lack of support from school and also the lack of time for planning the classes make the use of the reosurces still very limited. According to students' speech, the different teaching resources

https://orcid.org/0000-0002-8131-0697 - Mestre em Ensino na Educação Básica pelo Centro Universitário do Espírito Santo (CEUNES). Pesquisadora do Centro Universitário do Espírito Santo (CEUNES), São Mateus, Espírito Santo, Brasil. Rodovia BR 101 Norte, Km. 60, Bairro Litorâneo, 29932-540, São Mateus - ES. E-mail: lalyfracalossi@gmail.com

2 (iD https://orcid.org/0000-0002-4157-6503 - Doutora em Biologia Celular e Estrutural pela Universidade Estadual de Campinas (UNICAMP). Professora do Centro Universitário do Espírito Santo (CEUNES), São Mateus, Espírito Santo, Brasil. Rodovia BR 101 Norte, Km. 60, Bairro Litorâneo, 29932-540, São Mateus - ES. E-mail: julianacmonteiro@gmail.com

3 iD https://orcid.org/0000-0002-3564-2180 - Doutor em Entomologia pela Universidade Federal de Viçosa (UFV). Professor do Centro Universitário do Espírito Santo (CEUNES), São Mateus, Espírito Santo, Brasil. Rodovia BR 101 Norte, Km. 60, Bairro Litorâneo, 29932-540, São Mateus - ES. E-mail: marcosteixeiraufes@gmail.com

4 iD https://orcid.org/0000-0003-2043-1070 - Pós Graduada em Educação Ambiental pela Faculdades Integradas de Jacarepaguá (FIJ). Professora na Escola Estadual de Ensino Fundamental e Médio Pio XII, São Mateus, Espírito Santo, Brasil. Rua Coronel Constantino Cunha, 1890, Centro, 29930-360, São Mateus -ES. E-mail: camila_galletti@hotmail.com 
stimulated the desire to learn, to better understand the content, to clarify questions and to have a clearer view about the taught subject. Thereby, it was evident that the teaching resources contributed positively in the teaching/learning process.

Keywords: basic education, sciences, meaningful learning.

\section{Introdução}

Em um processo que se inicia no ensino fundamental e prolonga-se por toda a vida, o ensino de Ciências contribui para a compreensão da realidade que nos cerca. Aprender Ciências é aprender uma forma de pensar que contribui para ampliar nossa capacidade de ter uma visão crítica acerca da realidade que vivemos. O estudo de Ciências no ensino fundamental deve ajudar o aluno a compreender conceitos científicos básicos e a estabelecer relações entre estes e o mundo em que ele vive, levando em conta a diversidade dos contextos físico e cultural em que ele está inserido. Busca-se construir uma proposta de educação em Ciências que contribua para criar, no aluno, um conjunto de atitudes que permitam a melhoria de sua vida cotidiana, que o levem a enfrentar os problemas com maiores possibilidades de sucesso e atitudes de valorização de sua saúde e da sua comunidade (ARRUDA e RIBEIRO, 1999).

Uma das definições para o termo "didática" é o conjunto de princípios e técnicas que conduzem a aprendizagem de qualquer componente curricular (FREITAS, 2009). Contudo para Freitas (2009, p. 16), “As práticas educacionais cotidianas permitem constatar a necessidade urgente de um novo olhar sobre os suportes didáticos". Castoldi e Polinarski (2009, p. 685) afirma que, "a maioria dos professores tem uma tendência em adotar métodos tradicionais de ensino, por medo de inovar ou mesmo pela inércia, há muito estabelecida, em nosso sistema educacional". Desta forma, o processo de ensino/aprendizagem acaba se tornando muito dependente do livro didático.

"Os materiais e equipamentos didáticos são todo e qualquer recurso utilizado em um procedimento de ensino, visando à estimulação do aluno e à sua aproximação do conteúdo" (FREITAS, 2009, p. 22). A utilização de recursos didático-pedagógicos permite que os alunos participem do processo de aprendizagem e, com isso, além de expor o conteúdo de uma forma diferenciada, preenche lacunas que o ensino tradicional deixa (CASTOLDI e POLINARSKI, 2009). Os recursos didáticos fornecem informações, orientam a aprendizagem, exercitam habilidades, motivam, avaliam, fornecem simulações, fornecem ambientes de expressão e criação (GRAELLS, 2000). Porém, na maioria das vezes, alunos do ensino fundamental da rede pública se deparam com metodologias que nem sempre auxiliam na efetiva construção de seu conhecimento (LIMA e VASCONCELOS, 2006).

O aumento de gestações na adolescência é apontado por diversos fatores, entre eles: a antecipação da idade da menarca, a iniciação sexual precoce e a carência de orientação sexual adequada por parte dos pais e discussão e orientação a respeito da sexualidade na adolescência, pois é nessa fase que ocorrem as transformações corporais, hormonais e até mesmo comportamentais (LOPES, 2000), pois é nessa fase que ocorrem as transformações corporais, hormonais e até mesmo comportamentais.

De acordo com os Parâmetros Curriculares Nacionais (PCN), a partir do quarto ciclo, que é o último ciclo do ensino fundamental, é importante um melhor conhecimento das mudanças 
hormonais relacionadas ao amadurecimento sexual dos adolescentes e ao conhecimento das células sexuais, enfocando no processo de fecundação, gestação e parto. A partir desse ciclo, os alunos já possuem algum conhecimento sobre o processo de gravidez, sendo que a gravidez precoce e indesejada está relacionada à utilização inadequada ou a não utilização de métodos contraceptivos. Então, faz-se necessário a comparação de diversos métodos contraceptivos, sua correta utilização, modo de ação, eficiência e efeitos colaterais. Aproveitando essa discussão, é indispensável o conhecimento das doenças sexualmente transmissíveis, modos de transmissão, a prevenção e principais sintomas (BRASIL, 1998).

Um dos processos mais prejudicados pela ausência da diversidade de recursos didáticos é o ensino da reprodução humana para adolescentes. Estudantes do 8o ano do ensino fundamental estão experimentando mudanças em seu corpo e as dúvidas nesses momentos se tornam muito frequentes. Por isso, esse conteúdo é fundamental. Além disso, nessa fase da vida os estudantes esperam se envolver com atividades mais dinâmicas em detrimento das aulas expositivas ou centradas no livro didático. Espera-se que o uso de diferentes recursos didáticos no ensino de reprodução humana desperte ainda mais a atenção e interesse dos alunos. Nesse sentido, presente estudo analisou como o conteúdo de reprodução humana é ministrado, se são utilizados materiais didáticos, quais dificuldades encontradas pelos professores e alunos e, além disso, utilizou diferentes recursos didáticos e avaliou como esses recursos auxiliam na aprendizagem do conteúdo.

\section{Metodologia}

Para a coleta e análise de dados utilizou-se o método misto, onde a abordagem quantitativa (realista/objetivista) e qualitativa (visão idealista/subjetivista) foram empregadas.

Creswell define a abordagem mista:

[...] como aquela em que o pesquisador tende a basear as alegações do conhecimento em elementos pragmáticos, [...] e emprega estratégias de investigação que envolvem coleta de dados simultânea ou sequencial para melhor entender os problemas da pesquisa (2007, p.35).

Os dados quantitativos e qualitativos acabam se complementando dentro de uma pesquisa, pois as pesquisas quantitativas respondem a noções mais particulares e as qualitativas trabalham com motivações, crenças, valores e significados (MINAYO, 1996). Neste estudo, a abordagem qualitativa foi fundamentada na análise de conteúdo de Bardin (1977), que é um conjunto de técnicas de análise das comunicações que utiliza procedimentos sistemáticos e objetivos de descrição do conteúdo das mensagens.

A pesquisa foi desenvolvida com 18 professores do ensino fundamental II de escolas públicas e particulares, no município de São Mateus, norte do Espírito Santo. A utilização de diferentes recursos didáticos no ensino de reprodução humana foi com 56 alunos de duas turmas do 8 o ano do ensino fundamental do turno vespertino da Escola Estadual de Ensino Fundamental e Médio (EEEFM) "Pio XII", localizada no mesmo município. 
Para analisar se os professores se mantêm atualizados sobre o conteúdo de reprodução humana, como o conteúdo é ministrado e quais dificuldades são encontradas pelos professores e alunos, foram utilizados questionários semiestruturados que abordaram os seguintes conteúdos: fontes de atualização, recursos didáticos utilizados, dificuldades ao ministrar o conteúdo e se o uso de diferentes recursos didáticos facilita a aprendizagem do conteúdo.

Para aplicação dos recursos didáticos na escola, houve também um contato com a equipe pedagógica da escola e com a professora responsável pelos 8ㅇ anos, onde foram informados sobre o objetivo da pesquisa e o plano de trabalho (questionários e sequência didática).

Antes da utilização dos recursos didáticos foi aplicado um questionário para os alunos, abordando os seguintes conteúdos: fontes de atualização, assuntos do conteúdo que mais tem interesse em estudar, recursos didáticos que gostariam que fossem utilizados pelos professores e se o uso de diferentes recursos didáticos facilita a aprendizagem do conteúdo.

Para avaliar os benefícios e dificuldades (vantagens/desvantagens) do uso de diferentes recursos didáticos no ensino do conteúdo de reprodução humana foram utilizados os seguintes recursos didático: I) debate - "tira - dúvidas": os alunos tiravam suas dúvidas e curiosidades sobre o tema; II) trabalho em grupo "cronologia da vida": a turma foi dividida em cinco grupos, e sorteada uma fase da vida para cada grupo, III) vídeos seguidos de discussão; IV) jogo esquematizando a reprodução humana: consiste em sete esquemas dos principais órgãos e etapas da reprodução humana que apresentam lacunas referentes a partes do órgão em questão, que devem ser preenchidas pelas duas equipes dividas em sala de aula e ganha quem mais pontua; V) jogo "caminho da reprodução" que consiste em duas fileiras de 15 casas e um dado (com lados DIFÍCIL, MÉDIO, FÁCIL E CARTA EXTRA), sendo a turma dividida em dois grupos e os alunos devem jogar o dado e responder a pergunta referente ao lado do dado que sair ou tirar uma carta extra e ganha o jogo quem alcançar a "chegada" primeiro; e VI) baralho "reproduzindo" que é composto por 80 cartas, referentes ao sistema reprodutor feminino e masculino, métodos anticoncepcionais ou contraceptivos, doenças sexualmente transmissíveis e cartas de ação como "pule 1 jogador", "pule 2 jogadores", "inverte o jogo" e "descartecompre", sendo o objetivo conseguir juntar 5 cartas do mesmo assunto escolhido pelo participante.

Ao final das atividades, foi aplicado outro questionário e os dados foram analisados quantificando-se a frequência percentual das categorias apresentadas no questionário respondido pelos professores e alunos. Além disso, foi feita uma análise do conteúdo das perguntas abertas do questionário dos professores e alunos, organizado as categorias que surgiram em frequências percentuais.

A pesquisa orientou-se pela Resolução no 466/2012 do Conselho Nacional de Saúde que dispõe sobre as normas aplicáveis a pesquisas em com seres humanos, cujos procedimentos metodológicos que envolvam a utilização de dados diretamente obtidos ou de informações identificáveis ou que possam acarretar riscos maiores do que os existentes na vida cotidiana.

Para o desenvolvimento da pesquisa, os professores de ciências receberam um Termo de Consentimento Livre e Esclarecido (professores) informando sobre o projeto de pesquisa e assinaram os termos tomando ciência. Do mesmo modo, foi enviada carta à direção da escola 
participante solicitando autorização para o desenvolvimento da pesquisa. A identidade dos participantes não foi revelada, assim como não foram veiculadas imagens deles.

\section{Resultados e discussão}

\section{Questionários para professores da educação básica}

De acordo com Moreira et al. (2020, p. 126), “É essencial e positiva a adoção por parte do professor de métodos e estratégias que resultem na aquisição de conhecimentos utilizáveis e aplicáveis à vida do aprendiz, oportunizando, assim, uma relação dialógica entre a teoria e a prática". A diversidade de recursos didáticos possibilita ao professor superar as mais diversas possibilidades e limitações de uma turma, criando um ambiente que desperte a curiosidade e interesse dos alunos para diversos conteúdos do ensino de Ciências e Biologia, principalmente o de reprodução humana, que se torna ainda mais importante para alunos dos anos finais do ensino fundamental, que estão experimentando mudanças em seu corpo.

Para que haja uma aprendizagem significativa no ensino de reprodução humana, é preciso ultrapassar limites, criar alternativas, novos métodos de ensino e utilizar recursos que possibilitem que os alunos aprendam de forma mais dinâmica um conteúdo que é tão fundamental. Porém, "o papel do professor é de fundamental importância para que o uso de tais recursos alcance o objetivo" (LEITE, SILVA \& VAZ, 2005, p. 12) e para isso é preciso que os professores estejam motivados, capacitados e preparados.

Os resultados mostram que a maioria dos entrevistados ministram aulas de reprodução humana há mais de 10 anos (figura $1 \mathrm{~A}$ ), o que sugere uma maior experiência ao abordar os conteúdos e estratégias que facilitem o ensino/aprendizagem. Ao perguntar se utilizam recursos didáticos em suas aulas, apenas um professor disse não utilizar. Dentre os que utilizam as tecnologias de informação e de comunicação, mencionaram vídeos, aulas com data show, filmes e o Laboratório de Informática Educacional (LIED), como sendo os recursos mais utilizados por eles. Como Ferreira e Bianchetti (2005) afirmam, o ensino aliado às tecnologias possibilita uma aprendizagem mais interativa, onde o aluno participa ativamente do processo, podendo auxiliar na construção do conhecimento. Porém, o lúdico ainda é pouco utilizado pelos professores; muitos ainda desconhecem os benefícios proporcionados e, algumas vezes, não utilizam pela falta de tempo para planejar (figura 1B).

O conteúdo "reprodução humana" desperta o interesse e curiosidade dos alunos e, por isso, o professor necessita estar preparado. É importante que o professor tenha uma formação inicial de qualidade e, que, além disso, tenha uma formação continuada, possibilitando, assim, o domínio do conteúdo. A formação continuada permite ao professor ter "a capacidade de refletir sobre a própria prática, com o objetivo de aprender a interpretar, compreender e refletir a realidade social e à docência" (OLIVEIRA, 2007, p. 67). O professor deve estar em constante atualização, uma vez que ocorrem mudanças contínuas e descobertas de novas tecnologias nessa área e, segundo os resultados dessa pesquisa, todos os professores se mantêm atualizados e o principal meio de informação é a internet (figura 1C). Dentro dos assuntos que mais gostam de trabalhar no conteúdo de reprodução humana estão sistema reprodutor 

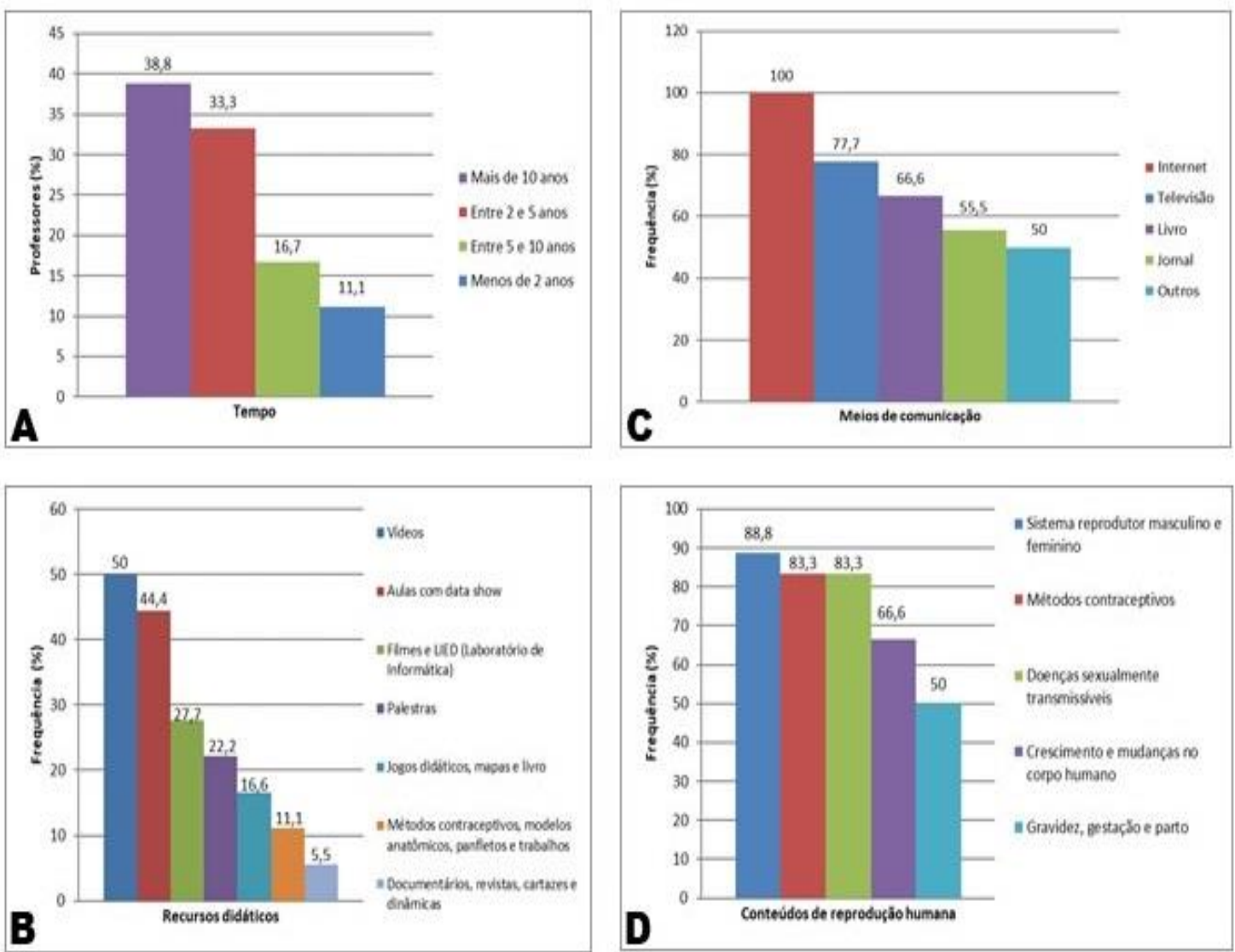

masculino e feminino, métodos contraceptivos e doenças sexualmente transmissíveis (figura 1D).

Figura 1: A- Tempo que os professores da educação fundamental ministram aulas de reprodução humana. B- Frequência de recursos didáticos utilizados pelos professores da educação básica nas aulas

de reprodução humana. C- Frequência de meios de comunicação utilizados pelos professores da educação básica para se manterem atualizados sobre o tema reprodução humana. D-Frequência de

conteúdos do tema reprodução humana que os professores da educação básica mais gostam de trabalhar.

A maioria dos entrevistados afirma não ter dificuldades ao trabalhar o conteúdo. Porém, alguns professores citam algumas dificuldades (quadro 1) e a principal está relacionada à imaturidade e comportamento dos alunos, onde apontam que os alunos não levam a sério os estudos e, nesse ponto, os recursos didáticos seriam uma ótima estratégia para despertar o interesse desses alunos. No entanto, infelizmente algumas escolas não conseguem oferecer recursos que deem suporte ao professor em sala de aula e isso acaba levando a uma dependência muito grande do livro didático.

Muitos professores relataram que possuem dificuldade em controlar a euforia da turma ao abordar esse conteúdo. Isso se deve ao fato de ser um momento em que estão ocorrendo as principais transformações biológicas do corpo e os alunos possuem muitas dúvidas e curiosidades sobre o conteúdo. Além disso, muitas vezes isso acontece porque os próprios pais não dão uma orientação adequada para os filhos, sendo essa outra dificuldade encontrada pelos 
professores, que muitas vezes se deparam com alunos sem nenhuma informação e, nesse momento, a escola acaba se tornando ainda mais importante. O conteúdo de reprodução humana possui muitos nomes específicos e os professores acabam tendo algumas dificuldades, principalmente nos nomes dos órgãos dos sistemas reprodutores, mas como afirmado por eles, não é nada que prejudique as aulas.

Quadro 1: Dificuldades apontadas pelos professores da educação básica para ministrar o conteúdo de reprodução humana.

\begin{tabular}{|c|c|l|}
\hline Categorias & Professores (\%) & \multicolumn{1}{|c|}{ Discurso } \\
\hline Não possuem dificuldades & 33,3 & \multicolumn{1}{|c|}{} \\
\hline Imaturidade/Comportamento & 27,8 & $\begin{array}{l}\text { Professor 1 -"Controlar a "euforia" das turmas ao } \\
\text { trabalhar com estes temas". } \\
\text { Professor 4 -"Falta de comprometimento dos } \\
\text { alunos com os estudos de maneira geral". } \\
\text { Professor 6-"Não deixar a aula se basear apenas } \\
\text { na curiosidade dos alunos, principalmente sobre os } \\
\text { métodos contraceptivos e sexo". } \\
\text { Professor 9 -"O desinteresse de alguns alunos". } \\
\text { Professor 17 -"Imaturidade dos alunos". }\end{array}$ \\
\hline Informação & 16,7 & $\begin{array}{l}\text { Professor 3 -“Os tabus advindos do histórico } \\
\text { familiar". } \\
\text { Professor 12 -“Total falta de informação dos } \\
\text { alunos e de suas famílias". }\end{array}$ \\
\hline Recursos & 11,2 & $\begin{array}{l}\text { Professor 10 -"Dificuldade "financeira" no que diz } \\
\text { respeito a recursos oferecidos pela escola". } \\
\text { Professor 14 -"Falta de recursos, materiais } \\
\text { didáticos". }\end{array}$ \\
\hline Linguagem & 5,5 & $\begin{array}{l}\text { Professor 8-"Linguagem adequada para facilitar a } \\
\text { compreensão do aluno, principalmente os de } \\
\text { ensino fundamental”. }\end{array}$ \\
\hline Conteúdo & $\begin{array}{l}\text { Professor 2 -“Às vezes há uma pequena } \\
\text { dificuldade na parte técnica (nome dos órgãos), } \\
\text { mas nada que prejudique o aprendizado". }\end{array}$ \\
\hline
\end{tabular}

Ao perguntar sobre o recurso didático como facilitador na aprendizagem do conteúdo, $61,3 \%$ dos professores disseram ajudar. Nós criamos seis categorias para sistematizar o conteúdo das falas dos professores e, de um modo geral, eles apontam que os recursos estimulam o interesse dos alunos, enriquece as aulas, o lúdico facilita a aprendizagem e a visualização dos métodos contraceptivos auxiliam na manipulação (quadro 2). Porém, ao analisar o quadro 2 e a figura $1 B$, percebe-se que o lúdico, dinâmicas e os métodos contraceptivos ainda são pouco utilizados nas aulas de reprodução humana. 
Quadro 2: Percepção dos professores da educação básica quanto à importância dos recursos didáticos como facilitadores na aprendizagem do conteúdo de reprodução humana.

\begin{tabular}{|c|c|c|}
\hline Categorias & Professores (\%) & Discurso \\
\hline Interesse & 11,2 & $\begin{array}{l}\text { Professor } 3 \text {-"Estimula o interesse e aguça a percepção por criar } \\
\text { conexões entre informações que antes estariam dissociadas". } \\
\text { Professor } 7 \text {-"Os alunos apresentam muito interesse sobre o } \\
\text { tema". }\end{array}$ \\
\hline Novidade & 5,5 & $\begin{array}{l}\text { Professor } 5 \text {-“Quanto mais novidades, mais atenção você vai } \\
\text { conseguir". }\end{array}$ \\
\hline Comportamento & 5,5 & $\begin{array}{l}\text { Professor } 4 \text {-“Sim, porém o aluno também tem que se } \\
\text { comprometer com o que está sendo ensinado". }\end{array}$ \\
\hline Lúdico & 5,5 & $\begin{array}{l}\text { Professor } 2 \text {-"Recursos mais lúdicos (vídeos, jogos, dinâmicas) } \\
\text { estreitam o espaço entre o aluno e professor facilitando a } \\
\text { aprendizagem". }\end{array}$ \\
\hline Visual & 5,5 & $\begin{array}{l}\text { Professor } 1 \text {-"A visualização dos métodos contraceptivos, por } \\
\text { exemplo, e a sua manipulação auxiliam na compreensão de } \\
\text { como devem ser utilizados. As animações favorecem a } \\
\text { compreensão dos ciclos hormonais, da transmissão de doenças, } \\
\text { etc". }\end{array}$ \\
\hline $\begin{array}{l}\text { Enriquecimento da } \\
\text { aula }\end{array}$ & 5,5 & Professor 6 -“Porque enriquece a aula”. \\
\hline
\end{tabular}

\section{Questionários para alunos antes do uso dos recursos didáticos}

Foram aplicados 56 questionários para os alunos antes da utilização dos recursos didáticos. Os resultados mostraram que a maioria deles busca se informar sobre o conteúdo e os principais meios de informação são a televisão e a internet (figura 2A). Como aponta Schmidt (2006, p. 6) "as crianças brasileiras passam uma média de cinco horas diárias na frente da televisão, ou seja, mais tempo que permanecem dentro da escola diariamente", e na maioria das vezes, é o que ocorre com a internet também. Porém, ao invés do professor ver a televisão e outros meios de comunicação como inimigos por serem julgados mais atraentes, a mídia deveria ser considerada como uma possível aliada na reconstrução do conhecimento, visto que os alunos chegam à idade escolar impregnados pela "cultura midiática" (SCHMIDT, 2006).

Os alunos entrevistados estão passando pela fase em que ocorrem as principais transformações corporais, hormonais e comportamentais, ou seja, é um período que envolve perdas e ganhos e que envolve a aceitação de uma imagem do corpo em mudança, como resultado da puberdade. Talvez, por esse motivo, os alunos apontaram o assunto crescimento e mudanças no corpo humano, como o conteúdo que mais interessam estudar no tópico reprodução humana, pois visam como um momento em que poderão sanar suas dúvidas e curiosidades, muito frequentes nessa fase da vida (figura 2B). Comparativamente com a frequência de conteúdos do tema reprodução humana que os professores da educação básica mais gostam de trabalhar (figura 1D), esse assunto não está entre os preferidos. Essa frequência 
pode estar relacionada com a insegurança em trabalhar com o tema ou até mesmo o comportamento dos alunos.
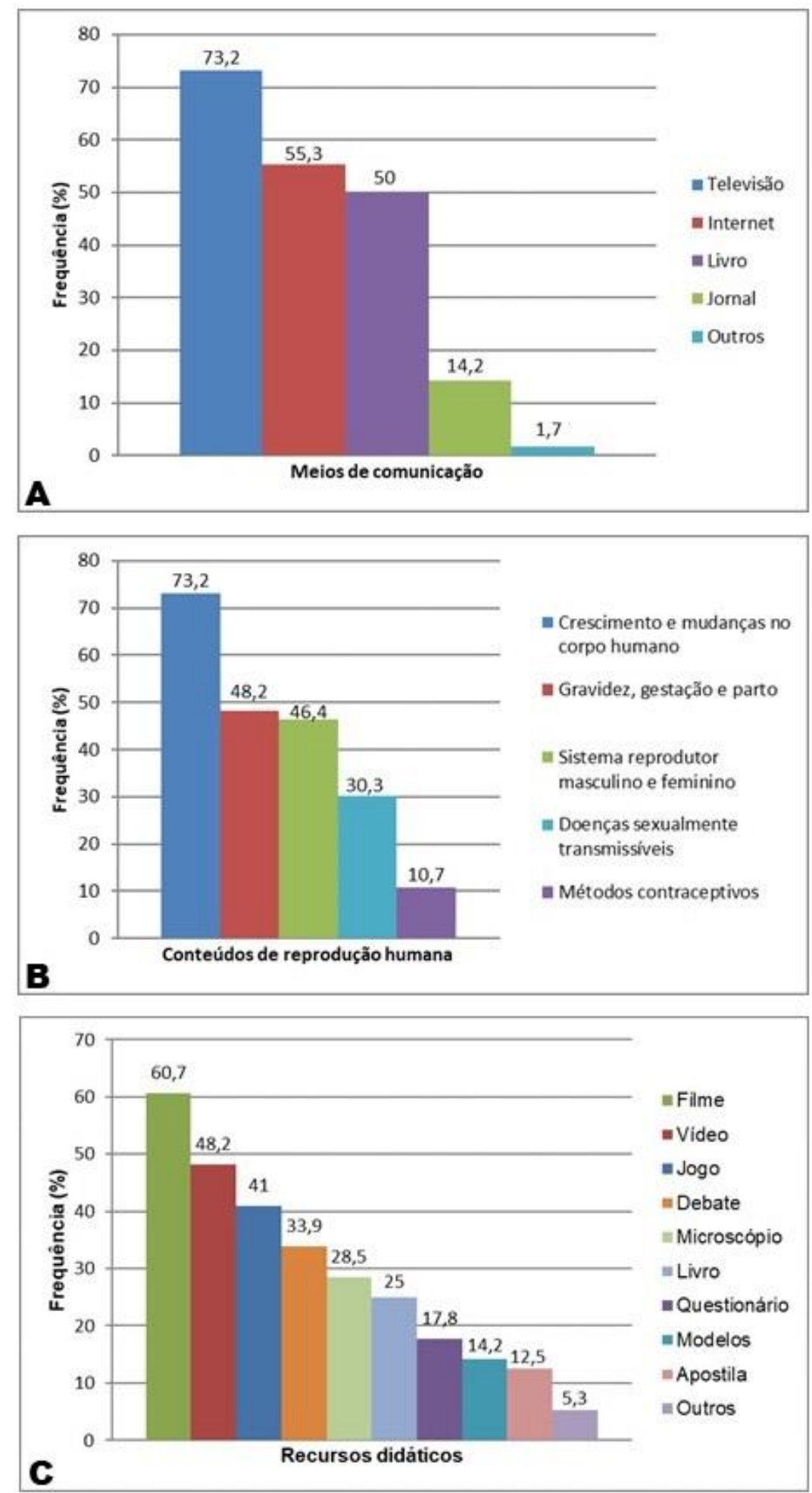

Figura 2: A- Frequência de meios de comunicação utilizados pelos alunos para se manterem atualizados sobre o tema reprodução humana. B- Frequência de conteúdos do tema reprodução humana que os alunos mais têm interesse em estudar. C- Frequência de recursos didáticos que os alunos gostariam que o professor utilizasse para ministrar o conteúdo de reprodução humana. 
Outro momento em que os recursos audiovisuais são novamente citados pelos alunos foi em relação aos recursos didáticos que os alunos gostariam que o professor utilizasse para ministrar o conteúdo de reprodução humana, onde o filme e vídeo ganham destaque (figura 2C). Os jogos didáticos aparecem logo em seguida na preferência dos alunos, já que é um recurso que desperta grande interesse, pois imaginam o processo ensino/aprendizagem aliado a diversão. O livro, questionários e apostila ficaram entre os recursos que os alunos menos têm interesse que o professor utilize em sala de aula, o que não é nenhuma surpresa, já que alunos dessa fase esperam se envolver com aulas mais dinâmicas e não com aulas que se baseiem apenas no tradicional. A maioria dos alunos disse que o uso de diferentes recursos didáticos ajudaria na aprendizagem do conteúdo de reprodução humana. Segundo Trivelato e Oliveira (2006, p. 2) "a utilização dos recursos didáticos pedagógicos diferentes dos utilizados pela maioria dos professores (quadro e giz), deixam os alunos mais interessados em aprender". Mas para que a aprendizagem seja significativa, deve se considerar cada fase, cada momento do ensino e as necessidades de aprendizagem de cada aluno, sendo preciso variar ao máximo a utilização dos recursos didáticos. Além disso, "o fator singular que mais influencia a aprendizagem é aquilo que o aprendiz já conhece. Descubra isso e ensine-o de acordo" (AUSUBEL, NOVAK e HANESIAN, 1980, p. 137).

\section{Questionários para alunos depois do uso dos recursos didáticos}

Os recursos didáticos possibilitam estimular os alunos, facilitar e enriquecer o processo ensino. O uso desses recursos para o ensino de Ciências e Biologia, permite que o professor deixe de ser apenas um transmissor do conhecimento e passe a mediar, construir e incentivar a aprendizagem do aluno. Após o uso dos recursos didáticos foi aplicado outro questionário para 46 alunos. Os resultados mostram que os assuntos de reprodução humana que os alunos mais gostaram de estudar foi o conteúdo sobre crescimento e mudanças no corpo humano. Esses alunos estão passando pela fase da adolescência, que é um período muito vulnerável e que cabe a família e aos educadores darem uma atenção especial, buscando orientá-los para lidarem com as diferentes situações do cotidiano. Antes do uso dos recursos didáticos, assuntos como gravidez, gestação e parto estavam entre os assuntos que os alunos mais tinham interesse em estudar e, depois do uso dos recursos didáticos, esses assuntos surgiram em menor porcentagem. Já com os métodos contraceptivos aconteceu o inverso, depois do uso dos recursos ficaram entre os assuntos que os alunos mais gostaram de estudar (figura $3 \mathrm{~A}$ ).

Os jogos didáticos foram os recursos que os alunos mais gostaram durante o conteúdo de reprodução humana, porém o debate e os vídeos também apresentaram uma porcentagem alta de aceitação (figura 3B). Lopes (2001, p. 23) afirma que "é muito mais eficiente aprender por meio de jogos e, isso é válido para todas as idades, desde o maternal até a fase adulta". Antes do uso dos recursos didáticos, os recursos audiovisuais tiveram destaque. O livro didático continuou sendo o recurso que os alunos menos gostam. 

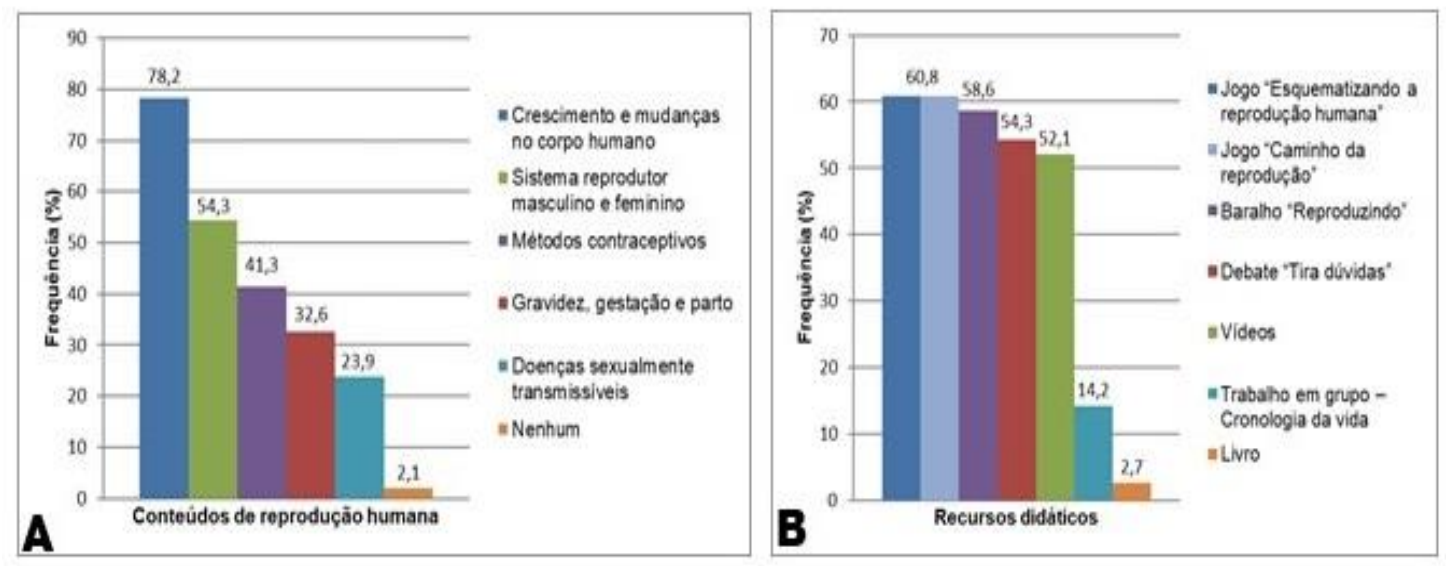

Figura 3: A- Frequência de conteúdos do tema reprodução humana que os alunos do 8o ano mais gostaram de estudar. $B$ - Recursos didáticos que os alunos do 8a ano mais gostaram durante o conteúdo de reprodução humana.

Considerando a avaliação dos alunos sobre os recursos didáticos aplicados, se auxiliaram no processo de ensino/aprendizagem do conteúdo, todos os alunos disseram ajudar. Das cinco categorias de respostas que criamos com base na fala dos alunos, a principal foi aprendizado, pois os alunos disseram que tiveram mais vontade de aprender, que auxiliou a compreender melhor o conteúdo, que a utilização de diferentes recursos ajudou e que conseguiram desenvolver mais com eles do que só com a professora explicando. Para Vigotsky (2001, p. 114) "o único bom ensino é o que se adianta ao desenvolvimento". Dentro das outras categorias, de um modo geral, apontam que os recursos ajudaram a tirar dúvidas, ao mesmo tempo em que aprendiam se divertiam, os vídeos possibilitaram ver a matéria com mais clareza e debater não só com a professora, mas também com os colegas (quadro 3). Nesta avaliação, 4,3\% dos alunos responderam apenas que sim.

Quadro 3: Avaliação dos alunos do 8o ano se os recursos didáticos auxiliaram no processo de ensino/aprendizagem do conteúdo de reprodução humana.

\begin{tabular}{|c|c|c|}
\hline Categoria & Alunos (\%) & Discurso \\
\hline Aprendizado & 65,3 & $\begin{array}{l}\text { Aluno } 1 \text {-“Ajudaram bastante no aprendizado, pois não era } \\
\text { a mesma coisa todos os dias. Um dia a gente assistia } \\
\text { vídeos, no outro era jogo, etc". } \\
\text { Aluno } 7 \text {-"Esses recursos são uma forma diferente de } \\
\text { aprendizagem, faz com que a aula não seja chata". } \\
\text { Aluno } 25 \text { - "Para mim sim, mas todos ajudaram um pouco, } \\
\text { enquanto um ajudou nas dst's os jogos e os vídeos nos } \\
\text { órgãos e suas funções". } \\
\text { Aluno } 28 \text {-"Sim, porque eu entendi melhor a matéria". } \\
\text { Aluno } 34 \text {-"Sim. Porque só a professora falando a gente } \\
\text { entenderia mais não o tanto que desenvolvemos com os } \\
\text { recursos aplicados". } \\
\text { Aluno } 36 \text {-"Eles ajudaram a aprender mais sobre os } \\
\text { conteúdos, tipo, algumas coisas que a gente não consegue } \\
\text { aprender na sala a gente aprendeu nos jogos, vídeos e } \\
\text { dinâmica". } \\
\text { Aluno } 38 \text {-“Ajudaram muito na minha aprendizagem, eu } \\
\text { acho que os jogos foram os melhores". }\end{array}$ \\
\hline
\end{tabular}




\begin{tabular}{|c|c|c|}
\hline & & $\begin{array}{l}\text { Aluno } 40 \text {-"A minha aprendizagem mudou muito, porque } \\
\text { me deu vontade de aprender mais. E depois eu vi também } \\
\text { que para aprender só basta querer. A reprodução humana } \\
\text { foi uma matéria que me interessou muito". }\end{array}$ \\
\hline Tirar dúvida & 15,2 & $\begin{array}{l}\text { Aluno } 2 \text {-"Sim. Pois eu tinha várias dúvidas, ai olhando os } \\
\text { vídeos tirei todas as dúvidas que eu tinha e com o baralho } \\
\text { também". } \\
\text { Aluno } 3 \text {-"Sim, porque eles tiraram minhas dúvidas e me } \\
\text { deixaram por dentro do assunto". } \\
\text { Aluno } 12 \text {-"Ajudaram muito. Quando tinha dúvidas os } \\
\text { recursos didáticos ajudaram". } \\
\text { Aluno } 16 \text {-"Sim ajudou muito, com o vídeo, as dúvidas que } \\
\text { eu tinha foram todas esclarecidas". } \\
\text { Aluno } 39 \text {-“Ajudou em muitas coisas, coisas que eu tinha } \\
\text { muita dúvida". } \\
\text { Aluno } 43 \text {-"Eu tinha dúvida sobre várias coisas e aprendi } \\
\text { melhor e mais rápido". }\end{array}$ \\
\hline Brincadeira/Diversão & 8,7 & $\begin{array}{l}\text { Aluno } 18 \text {-“Ajudou sim, aprendemos brincando". } \\
\text { Aluno } 11 \text {-"Eu achei bem legal, além de divertir, ajudou na } \\
\text { aprendizagem sobre a reprodução humana". } \\
\text { Aluno } 19 \text {-"Eu gostei dos recursos didáticos por que no } \\
\text { mesmo tempo que a gente brincava aprendia". }\end{array}$ \\
\hline Visual & 4,3 & $\begin{array}{l}\text { Aluno } 24 \text {-“Me ajudaram principalmente os vídeos que eu } \\
\text { pude ver com mais clareza”. }\end{array}$ \\
\hline Debate & 2,2 & $\begin{array}{l}\text { Aluno } 21 \text {-“Achei legal foi divertido, a gente pode debater } \\
\text { não só com a professora mais sim com os colegas". }\end{array}$ \\
\hline
\end{tabular}

\section{Conclusão}

O desenvolvimento do presente estudo possibilitou uma análise de como o conteúdo de reprodução humana está sendo ministrado, uma reflexão acerca dos benefícios dos recursos didáticos e dificuldades encontradas ao trabalhar esse conteúdo no ensino fundamental II em escolas públicas e particulares, no município de São Mateus, norte do Espírito Santo. Além disso, também permitiu utilizar diferentes recursos didáticos e avaliar como esses recursos auxiliam na aprendizagem do conteúdo, com duas turmas do 8 o ano do ensino fundamental do turno vespertino da Escola Estadual de Ensino Fundamental e Médio (EEEFM) "Pio XII", localizada no mesmo município.

De um modo geral, os professores demonstraram interesse em trabalhar o tema em sala de aula e buscam meios para estarem atualizados, mas ainda possuem algumas dificuldades, como controlar a euforia da turma, estimular o interesse dos alunos e com os recursos oferecidos pela escola. A maioria dos professores utiliza recursos didáticos em suas aulas, mas a falta de apoio da escola e falta de tempo para planejar faz com que o uso dos recursos ainda fique muito limitado, sendo que as turmas e mesmo os alunos da mesma turma possuem perfis diferenciados.

Os alunos também demonstraram muito interesse pelo tema e buscam se informar, principalmente pela televisão e internet. A maioria dos alunos mencionou que o uso de recursos didáticos ajudaria na aprendizagem do conteúdo de reprodução humana e destacaram o filme e o vídeo, como recursos que gostariam que o professor utilizasse nas aulas. 
Após a aplicação dos recursos didáticos, os resultados mostraram que o assunto de reprodução humana que os alunos mais gostaram de estudar foi crescimento e mudanças no corpo humano, o mesmo citado antes do uso dos recursos, o que sugere uma relação com a fase em que estão passando, na qual as dúvidas e curiosidades são muito frequentes.

Dentre os recursos utilizados, os jogos didáticos foram o que os alunos mais gostaram, porém o debate e os vídeos também apresentaram alta aceitação. Diante das falas dos alunos, os diferentes recursos estimularam a terem mais vontade de aprender, a compreender melhor o conteúdo, a tirar dúvidas e ter uma visão mais clara da matéria. Desse modo, ficou evidente que os recursos didáticos ajudaram no processo de ensino/aprendizagem.

Dada à importância do tema, torna-se necessário o desenvolvimento de projetos que visem à formação continuada dos professores, que possam desencadear competências e habilidades para garantir um ensino de maior qualidade, que atendam as diferentes necessidades dos alunos e, assim, efetivar uma prática pedagógica diferenciada.

\section{Referências}

AUSUBEL, D. P.; NOVAK, J. D.; HANESIAN, H. Psicologia educacional. Rio de Janeiro, RJ: Interamericana, $1980.625 \mathrm{p}$.

ARRUDA, M. A. S.; RIBEIRO, I. F. P. Ciências Naturais no Ensino Fundamental. In: Projeto curricular para o ensino fundamental e para o ensino médio: ciências da natureza, matemática e suas tecnologias. Rio de Janeiro: Fundação Darcy Ribeiro, 1999.

BARDIN, L. Análise de conteúdo. Lisboa: Edições 70, 1977. 225 p.

BRASIL. Parâmetros Curriculares Nacionais: Ciências Naturais. Brasília: MEC/SEF, 1998. 138 p.

CASTOLDI, R; POLINARSKI, C. A. A utilização de Recursos didático pedagógicos na motivação da aprendizagem. In: SIMPÓSIO NACIONAL DE ENSINO DE CIENCIA E TECNOLOGIA, I, 2009, Ponta Grossa. Anais... I Simpósio Nacional de Ensino de Ciência e Tecnologia - SINECT, Ponta Grossa: UTFPR, 2009. p. 684-692.

CRESWELL, J. W. Projeto de pesquisa: métodos qualitativo, quantitativo e misto. 2. ed. Porto Alegre, RS: Artmed, 2007. 126 p.

FERREIRA, S. L.; BIANCHETTI, L. As tecnologias de informação e de comunicação e as possibilidades de interatividade para a educação. In: PRETTO, N. L. (Org.). Tecnologias e novas educações. Salvador: Edufba, 2005. p. 153-165.

FREITAS, O. Equipamentos e materiais didáticos. Brasília: Universidade de Brasília, 2009.132 p.

GRAELLS, P. M. Los medios didácticos. In: PLANEACIÓN didáctica con TIC. Barcelona: UAB, 2000. Disponível em:

http://tic.sepdf.gob.mx/micrositio/micrositio1/docs/materiales_estudio/u3_13/Los_medios_di dacticos.pdf > Acesso em: 02 jul. 2013. 
LEITE, A.C.; SILVA, P.A.B.; VAZ, A.C.R. A importância das aulas práticas para alunos jovens e adultos: uma abordagem investigativa sobre a percepção dos alunos do PROEF II. Revista Ensaio Pesquisa em Educação em Ciências, Belo Horizonte, v. 7, n. 3, p. 1-16. 2005.

LIMA, K. E. C; VASCONCELOS, S. D. Análise da metodologia de ensino de ciências nas escolas da rede municipal de Recife. Avaliação de políticas públicas Educacionais, Rio de Janeiro, v. 14, n. 52, p. 397-412, jul./set. 2006.

LOPES, M. G. Jogos na Educação: criar, fazer e jogar. 4. ed. São Paulo: Cortez, 2001. 23 p.

MINAYO, M. C. S. (Org.). Pesquisa Social: Teoria, Método e Criatividade. 6 ed. Petrópolis: Vozes, 1996.

MOREIRA, E. S. G.; SOUZA, M. J. F. S.; SILVA, E. L.; SANTOS, K. A. L. o vídeo como recurso didático: uma intervenção pedagógica sobre o uso da água. Ensino de Ciências e Tecnologia em Revista, Santo Ângelo, v. 10, n. 2, p. 114-128, mai./ago. 2020.

LOPES, G. Gravidez na Adolescência: Política Prioritária e Saúde. Jornal da FEBRASGO, 7(3): 4$5,2000$.

OLIVEIRA, V. L. B. Fronteiras do conhecimento escolar: o tema da reprodução assistida e a formação continuada de professores de Biologia. 2007. 262 f. Tese (Doutorado em educação) Programa de Pós- Graduação em Educação Científica e Tecnológica, Universidade Federal de Santa Catarina, Florianópolis, 2007.

SCHMIDT, S. Em pauta: a aliança mídia e educação. Unirevista, São Leopoldo, v. 1, n. 3, p. 1-8, jul. 2006. Disponível em: http://www.alaic.net/ponencias/UNIrev_Schmidt.pdf. Acesso em: março de 2011.

TRIVELATO, S. L. F.; OLIVEIRA, O. B. Pratica docente: o que pensam os professores de ciências biológicas em formação. Revista Teias, Rio de Janeiro, ano 7, n. 13-14, p. 1-11, jan./dez. 2006.

VIGOTSKY, L. S. A construção do pensamento e da linguagem. São Paulo: Martins Fontes, 2001. $496 \mathrm{p}$. 